Research Article

\title{
Assessment of vaccine wastage in the immunization clinic attached to S. P. Medical College, Bikaner, Rajasthan
}

\author{
Gaurav Sharma*, Renu Sethia, Rekha Acharya, Ratti Ram Meena
}

Department of PSM, S. P. Medical College, Bikaner, Rajasthan, India

Received: 06 January 2016

Accepted: 04 February 2016

\author{
*Correspondence: \\ Dr. Gaurav Sharma, \\ E-mail: g.sha37@gmail.com
}

Copyright: ( ) the author(s), publisher and licensee Medip Academy. This is an open-access article distributed under the terms of the Creative Commons Attribution Non-Commercial License, which permits unrestricted non-commercial use, distribution, and reproduction in any medium, provided the original work is properly cited.

\begin{abstract}
Background: India released its first National Vaccine Policy in 2011. The country is presently developing new strategies to increase immunization coverage and reach more children with quality vaccine. High vaccine wastage increase vaccine demand and inflate overall program cost.

Methods: This was records based descriptive study carried out at Immunization Clinic, Sardar Patel Medical College, Bikaner, Rajasthan. The information regarding vaccine vials used at Immunization Clinic and children vaccinated were retrieved from Immunization register for the reference period 1st April 2014 to 31st March 2015.

Results: Among individual vaccine, wastage factor and rates was highest (1.42 and 29.45\% respectively) for Oral Polio Vaccine (OPV) and lowest (1.10 and 9.21\% respectively) for Hepatitis-B vaccine. The wastage rate for multidose vial was $27.66 \%$ for 5 doses vial, $13.88 \%$ for 10 doses vial and highest $29.45 \%$ for 20 doses vials. Among vaccines wastage rate of lyophilized vaccines $(23.30 \%)$ were higher when compared to liquid vaccines $(20.66 \%)$.

Conclusions: Vaccine wastage rate can be obtained by monitoring of the immunization centre. Monitoring vaccine wastage will help not only to improve quality of the programme but it will also increase the efficiency of the programme. This can thus help save significant funds for an immunization programme.
\end{abstract}

Keywords: Vaccine wastage rate, BCG, DPT, OPV, Pentavalent, Hepatitis-B

\section{INTRODUCTION}

India's universal immunisation programme is among the largest in the world and is available for all children in the country free of charge. Almost 10 million of the 27 million children born in India every year are either not vaccinated or receive partial coverage. And it has been estimated that a third of the 1.5 million deaths among children every year could be prevented with vaccines. ${ }^{1}$

Universal Immunization Programme (UIP) budget is more than USD 500 million every year for immunizing children against vaccine preventable disease, including the polio eradication programme. The country is presently developing new strategies to increase immunization coverage and reach more and more children with quality vaccines, the current measure being
Mission "Indradhanush", which was launched in December 2014. ${ }^{2}$ These efforts are challenged by the problems of securing adequate quality and quantity of vaccine for the programme. In addition, deficiencies in vaccine management and high wastage increase vaccine demand and inflate overall programme cost.

India released its first National Vaccine Policy in 2011 and the published outcome on vaccination coverage shows that it is more than $70 \%$ in only 11 states, $50-70 \%$ in 13 states and is below $50 \%$ in remaining 8 states; and Rajasthan (DLHS-4) is amongst these eight states with vaccine coverage of $48.7 \%$ only. ${ }^{3,4}$

Vaccine wastage can be classified as those occurring in unopened vials and those which in opened vials. Expiry, as by Vaccine Vial Monitor (VVM) indication, heat 
exposure, freezing, breakages are forms of vaccine wastage affecting unopened vials. Vaccine wastage in opened vials may occur as the dose remaining in opened vial at the end of session are discarded, the number of doses drawn from a vial is not always the same as that indicated on the label, reconstitution practices are poor, open vials are submerged in water and also wastage occurs when contamination is suspected and the vaccine is discarded. ${ }^{5}$

WHO reports vaccine wastage to be over $50 \%$ all around the World. The lack of knowledge of vaccine wastage rates leads to inadequate estimation of needs and thereby leading to problems of vaccine being out of stock and /or there is excess stock of vaccine. High vaccine wastage rate inflate vaccine demands and increase unnecessary vaccine procurement and supply chain costs. The Ministry of Health and Family Welfare, Government of India has recommended that vaccine wastage rate should not more than $25 \% .^{6}$

There is dearth of comprehensive study done in India to validate the vaccine wastage rates recommended by WHO and The Ministry of Health and Family Welfare, Government of India and also there are few studies on wastage rate of vaccines, published in India. This article attempts to calculate the vaccine wastage rates in Immunization Clinic of a Medical College at Bikaner, Rajasthan in context to vaccine management policy.

\section{METHODS}

This was records based descriptive study carried out at Immunization Clinic attached to Sardar Patel Medical College, Bikaner, Rajasthan. DPT, OPV, Measles, Hepatitis-B administrated in this immunization centre as per National Immunization Schedule. Pentavalent vaccine was introduced in Rajasthan in November 2014. Children born before November 2014 continue to receive DPT and those who were born afterwards were given Pentavalent vaccine.

BCG, DPT, Pentavalent and Hepatitis-B vaccine vials used have 10 doses per vial, Measles vials 5 doses per vial and OPV 20 doses per vial. DPT, OPV, Pentavalent, Hepatitis-B are supplied as liquid formulation and BCG and Measles in lyophilized forms. Multi-dose vaccine vials policy was followed in Clinic, which allows reusing all liquid vaccine vials which have been taken out for immunization and returned unopened at least three times or that has been kept in cold storage for 28 days, and as per recommendation for lyophilized vaccines all vials are discarded after 4-6 hours of reconstitution. ${ }^{3}$

The information of vaccine vials used at Immunization Clinic and children vaccinated were retrieved from immunization register for the reference period $1^{\text {st }}$ April 2014 to $31^{\text {st }}$ March 2015.

Vaccine wastage rate was calculated as follows:
Vaccine wastage rate $=$ No. of dose wasted $/$ No. of doses issued $\mathrm{x} 100$.

Vaccine wastage factor was calculated as:

Vaccine wastage factor $=100 / 100$-vaccine wastage rate ${ }^{5}$

The information of vaccine vials used was entered into Microsoft Excel sheet and data was tabulated for statistical analysis.

\section{RESULTS}

A total 365 immunization sessions were conducted during reference period and 6 vaccines (BCG, DPT, OPV, Measles, Hepatitis-B, and Pentavalent) were given to children. A total 6975 vaccine vials (80220 doses) issued and 63145 children were immunized.

Among individual vaccine, wastage factor and rates was highest (1.42 and $29.45 \%$ respectively) for OPV and lowest (1.10 and $9.21 \%$ respectively) for Hepatitis-B (Table 1).

Table 1: Vaccine wastage rate and wastage factor for different vaccines.

\begin{tabular}{|llll|}
\hline Vaccine & $\begin{array}{l}\text { Dose } \\
\text { issued }\end{array}$ & $\begin{array}{l}\text { Number of } \\
\text { children } \\
\text { vaccinated }\end{array}$ & $\begin{array}{l}\text { Wastage rate } \\
\text { \% (wastage } \\
\text { factor) }\end{array}$ \\
\hline BCG & 12930 & 10176 & $21.30 \%(1.27)$ \\
\hline DPT & 10220 & 8916 & $12.76 \%(1.15)$ \\
\hline OPV & 32860 & 23181 & $29.45 \%(1.42)$ \\
\hline Hepatitis- B & 14120 & 12819 & $9.21 \%(1.10)$ \\
\hline Measles & 5960 & 4311 & $27.67 \%(1.38)$ \\
\hline Pentavalent & 4130 & 3742 & $9.39 \%(1.10)$ \\
\hline
\end{tabular}

The vaccines were supplied in 3 different sizes of vials i.e 5 doses vial (Measles), 10 doses vial (DPT, Pentavalent, BCG, Hepatitis-B) and 20 doses vial (OPV). It was observed that wastage rate was $27.66 \%$ for 5 doses vial, $13.88 \%$ for 10 doses vial and $29.45 \%$ in 20 doses vial which was highest (Table 2).

Table 2: Vaccine wastage rate and wastage factor for different multi-dose vial vaccine.

\begin{tabular}{|llll|}
\hline Dose/vial & $\begin{array}{l}\text { Dose } \\
\text { issued }\end{array}$ & $\begin{array}{l}\text { Number } \\
\text { of } \\
\text { children } \\
\text { vaccinated }\end{array}$ & $\begin{array}{l}\text { Wastage } \\
\text { rate \% } \\
\text { (wastage } \\
\text { factor) }\end{array}$ \\
\hline 5 doses/vial & 5960 & 4311 & $27.66 \%(1.38)$ \\
\hline 10 doses/vial & 41400 & 35653 & $13.88 \%(1.16)$ \\
\hline 20 doses/vial & 32860 & 23181 & $29.45 \%(1.42)$ \\
\hline
\end{tabular}

The vaccines come in lyophilized and liquid forms. Four vaccines DPT, OPV, Pentavalent, and Hepatitis -B are supplied in liquid form and two vaccine Measles and BCG are supplied in lyophilized form. Among these 
wastage rate for lyophilized vaccines (23.30\%) were higher when compared to liquid vaccines $(20.66 \%)$ (Table 3).

Table 3: Vaccine wastage rate and wastage factor for lyophilized and liquid vaccine.

\begin{tabular}{|llll|}
\hline $\begin{array}{l}\text { Vaccine } \\
\text { type }\end{array}$ & $\begin{array}{l}\text { Dose } \\
\text { issued }\end{array}$ & $\begin{array}{l}\text { Number of } \\
\text { children } \\
\text { vaccinated }\end{array}$ & $\begin{array}{l}\text { Wastage rate } \\
\% \text { (wastage } \\
\text { factor) }\end{array}$ \\
\hline Lyophilized & 18890 & 14487 & $23.30 \%(1.30)$ \\
\hline Liquid & 61330 & 48658 & $20.66 \%(1.26)$ \\
\hline
\end{tabular}

All the vaccines except OPV are administrated through injection. The Wastage Rate of Oral vaccine $(29.45 \%)$ was higher compared to inject able vaccines $(15.61 \%)$ (Table 4).

\section{Table 4: Vaccine wastage rate and wastage factor for different modes of administration.}

\begin{tabular}{|llll|}
$\begin{array}{l}\text { Mode of } \\
\text { administ- } \\
\text { ration }\end{array}$ & $\begin{array}{l}\text { Dose } \\
\text { issued }\end{array}$ & $\begin{array}{l}\text { Number of } \\
\text { children } \\
\text { vaccinated }\end{array}$ & $\begin{array}{l}\text { Wastage rate } \\
\% \text { (wastage } \\
\text { factor) }\end{array}$ \\
\hline Injection & 47360 & 39964 & $15.61 \%(1.18)$ \\
\hline Oral & 32860 & 23181 & $29.45 \%(1.41)$ \\
\hline
\end{tabular}

\section{DISCUSSION}

During immunization the number of vaccine doses utilized is always higher than number of beneficiary actually immunized. Excess number depicts wastage. The Ministry of Health and Family Welfare, Government of India has recommended that wastage rate of all vaccines should not higher than $25 \%$ (wastage factor 1.33) and as per recommendation by WHO, projected vaccine wastage rate for lyophilized vaccine is expected to be $50 \%$, wastage rate for 10-20 dose vials and liquid vaccine $25 \% .^{7,11}$

The present study showed that all vaccine wastage rates were within the limits provided by Ministry of Health and Family Welfare and WHO except for OPV.

OPV wastage rate were slightly higher. Similar pattern obtained in other studies such as those conducted by UNICEF (47\%), Palanivel Cet al (48.1\%) and Mukherjee et al $(52.7 \%)$ though wastage rates higher than from our study $(29.45 \%)^{5,9,10}$

The higher wastage rate for OPV may be due to the fact that wastage of OPV occurs at the time of administrating the vaccine due to faulty vaccination technique of vaccinators, child moving head at the time of ingestion of vaccine, OPV being the most heat sensitive and also the OPV vial having the maximum doses per vial.

The wastage rate for different vials having different doses per vial showed that wastage rate for 5 doses vaccine vial was $27.66 \%$, wastage rate for 10 doses vaccine vial was $13.88 \%$ and wastage rate for 20 doses vaccine vial was the highest at $29.45 \%$ though they were lower than the wastage rate obtained by Palanivel $\mathrm{C}$ et al and Mehta $\mathrm{S}$ et $\mathrm{al}^{7,10}$ The higher the number of doses in vials the higher will be the wastage if the number of beneficiary attending immunization session is less but as the multi-dose vial is more cost effective a balance needs to be maintained regarding wastage of vaccine and cost of immunization using multi-dose vial.

The present study showed that the vaccine wastage for liquid $(20.66 \%)$ and lyophilized $(23.30 \%)$ was in the limits provided by Ministry of Health and Family Welfare and WHO. The wastage rate was higher in lyophilized vaccine when compared to that of liquid vaccine. Similar pattern also show in other studies of UNICEF (38\%-liquid, 50\%-lyophilized), Mehta S et al (20.16\%-liquid, 37.8\%-lyophilized), Praveena et al (3.4\%-liquid, 28.2\%-lyophilized). ${ }^{5,7,8}$

The present study showed that wastage rate for oral vaccine $(29.45 \%)$ is higher compared to inject able vaccines $(15.61 \%)$. Similar pattern also observed by Mehta $S$ et al (22\% inject able and $25 \%$ oral vaccine) and UNICEF ( $35 \%$ inject able and $47 \%$ oral vaccine). ${ }^{5,7}$ Now with elimination of Polio from India and in future introduction of injection for Polio vaccine this will be taken care of.

\section{CONCLUSION}

Vaccine wastage can be expected in all programmes and there should be acceptable limit of wastage. This might differ from location depending on many factors like urban and rural setting, immunization coverage etc. A high wastage rate attributed to opening a multi-dose vial for a small session size in order to avoid missed opportunities is more acceptable than wastage attributable to freezing or expiry. Higher wastage rates are acceptable to increased vaccine coverage in a low vaccine coverage setting. Vaccine wastage due to operational causes can be reduced by continued training and retraining of workers involved in immunization practices. Innovative techniques and more multivalent vaccines need to be developed to not only reduce wastage and operational cost but also for convenience of children who are to be vaccinated and parents who bring their children for vaccination.

\section{Funding: No funding sources Conflict of interest: None declared \\ Ethical approval: The study was approved by the Institutional Ethics Committee}

\section{REFERENCES}

1. Available from: https://www.researchgate.net/ publication/277594217_Mission_Indradhanush_targ 
ets_India\%27s_unvaccinated _children. Accessed Dec 14, 2015.

2. Cheryl T. Mission Indradhanush targets India's unvaccinated children. The BMJ. 2015;350:h1688.

3. National Immunization Technical Advisory Group. National vaccine policy. New Delhi: Ministry of Health and Family Welfare, Government of India. 2011.

4. NHM Health Management Information System (HMIS) Portal. Result of District Level Household Survey-IV. New Delhi: Ministry of Health and Family Welfare, Government of India. 2012-13.

5. UNICEF. Vaccine wastage assessment: field assessment and observations from National stores and five selected state of India. New York; UNICEF. 2010. Available at http://www.unicef.org /India/vaccine_wastage_ assessement_india pdf. Accessed on 10 December 2015.

6. Department of Health and Family Welfare. Immunization handbook for medical officers. New Delhi: Ministry of Health and Family Welfare, Government of India. 2008:31-2.

7. Mehta S, Umrigar P, Patel P, Bansal RK. Evaluation of vaccine wastage in Surat. Nat J Community Med. 2013;(4):15-9.

8. Praveena DA, Selvaraj K, Veerkumar AM, Nair DM. Vaccaine wastage assessement in primary care setting in rural India. Int. J Contemp Pediatr. 2015;2:7-11.

9. Mukherjee A, Ahluwalia TP, Gaur LN, Mittal R, Kambo I, Saxena NC, et al. Assessment of Vaccine Wastage during a Pulse Polio Immunization Programme in India. $\mathbf{J}$ Health Popul Nutr. 2004;22(1):13-8.

10. Palanivel C, Kulkarni V, Kalaiselvi S, Baridalyne $\mathrm{N}$. Vaccine wastage assessment in primary care setting in urban India. Journal of Pediatric Sciences. 2012;4(1)119.

11. WHO. Monitoring vaccine wasting at country, Geneva: WHO. 2011. Available at www.who.int/ vaccine_document. Accessed on 10 March 2015.

Cite this article as: Sharma G, Sethia R, Acharya R, Ratti RM. Assessment of vaccine wastage in the immunization clinic attached to s. P. Medical College, Bikaner, Rajasthan. Int J Community Med Public Health 2016;3:675-8. 